\title{
Alfabetização: um desafio para um novo tempo
}

\author{
Literacy: a change for a new time \\ L'alphabétisation: un défi pour un temps \\ nouveaus
}

Fabiana Castelo Branco de SANTANA

\section{RESUMO}

Diante da sociedade atual em que a escola precisa estar apta para formar indivíduos prontos para assumirem novos saberes, o conceito de alfabetização supera a definição de ser apenas a aquisição da técnica de decifração e codificação dos signos linguísticos. Nesse sentido, ser alfabetizado apresenta-se como a possibilidade de utilização de tais conhecimentos em benefício de formas de expressão e comunicação em um determinado contexto cultural. Por conseguinte, este artigo traz um eimbate entre duas concepções de ensino antagônicas; a empirista, observada através da experiência de estágio, e a construtivista, defendida neste trabalho. A partir daí, é realizada uma reflexão deste confronto, vislumbrandồ iniciativas pedagógicas que valorizem a criança como sujeito de sua própria aprendizagem.

Palavras-chave: alfabetização, empirista, construtivista, iniciativas pedagógicas.

\section{ABSTRACT}

In face of the current society, in that the school must be capable to form prepared people to get different knowledge, the literacy concept overcomes the definition of being just the acquisition of the decipher technique and code of the linguistic signs. In this sense, being alphabetized comes as the possibility of use of such knowledge in benefit of expression ways and communication in a certain cultural context. Consequently, this article brings and shock among two antagonistic teaching conceptions; the empiricist, observed through the experience in period of training and the constructivist that is defended in this work. Starting from there, a reflection about this confront is accomplished and pedagogic initiatives that value the child as subject of its own learning are shimmered.

Index terms: literacy, empirics, constructivist, pedagogic initiatives. 


\section{RÉSUMÉ}

Face à la société actuelle où l'école doit être capable de former des individus prêts à prendre de nouveaux savoirs, le concept de l'alphabétisation surpasse la définition d'être seulement l'acquisition de la technique de déchiffrer et codifier les signes linguistiques. Dans ce sens, être alphabétisé, est la possibilité d'utiliser de tels savoirs au profit de formes d'expresésion et de communication dans un contexte culturel déterminé. Par conséquent, cet article presente une confrontation entre deux conceptions antagonistes d'enseignement: l'empiriste observée par l'expérience du stage et la constructiviste défendue dans ce travail. À partir de là, une réflexion de cette confrontation est faite afin $\mathrm{d}$ 'envisager des initiatives pédagogiques qui donnent de la valeur à l'enfant en tant que sujet de son propre apprentissage.

Mots-clés: alphabétisation, empiriste, constructiviste, iniciatives pédagogiques

\section{Introdução}

A crescente preocupação por parte de muitos educadores com $\diamond$ processo da aquisição da leitura e da escrita pelas crianças tem proporcionado um aumento nos estudos sobre este tema. Sendo assim, nos dias atuais, surge uma grande polêmica quando se questiona qual a melhor maneira para alfabetizar uma criança diante das necessidades e exigências atuais da sociedade contemporânea.

O presente artigo tem como objetivo de, a partir das experiências vividas na disciplina Estágio Supervisionado nas Séries Iniciais do Primeiro Ciclo, analisar e refletir a prática docente na alfabetização, seus desafios e possibilidades, atentando para a importância de se ter bem definido pelo educador o seu objetivo ao alfabetizar o sujeito, seja para torná-lo agente do processo de mudança ou alheio às possibilidades de interagir no meio social.

Realizado por meio de pesquisa bibliográfica e pautado nas etapas de estágio proposto pela disciplina, este trabalho interessa aos profissionais e estudantes da área de Educação e os demais interessados no assunto. 


\section{Alfabetização: uma necessidade social}

A educação é constituída pelas sociedades dependendo das suas necessidades. Nas sociedades primitivas, a educação era algo natural, passada de pai para filho, onde o seu foco era o próprio exercício do viver. Nas sociedades agrárias, procedimentos rudimentares de leitura, escrita e cálculo eram suficientes para a integração social e profissional, o que não satisfaria a Sociedade Moderna. A exigência de escolaridade para todos foi trazida pela Revolução Industrial e o século XX com a Revolução Tecnológica, trouxe a exigência da formação de um novo homem.

Um profissional que apenas apertava botões ou openava mecanicamente uma alavanca, não se encaixa mais nos padrões desta nova ordem. As máquinas, cada vez sofisticadas, demandam novos saberes, exigindo daqueles que tinham como única função operá-las, competências diversificadas. Faz-se necessário interagir, inserir dados, reagir conforme as etapas do processo, realizar a correta leitura dos elementos apresentados, ter agilidade mental para interferir com rapidez e no momento exato, ou seja, a exigência deste novo tempo é saber pensar. E para corresponder a esta complexidade é preciso oferecer melhor formação àqueles que atuarãon nela.

Num mundo em que tudo se supera rapidamenté, em que as mudanças se dão não ao ritmo de séculos ou de décadas, mas de ano para ano, a expectativa que se tem é a de um profissional sempre pronto para assumir novos saberes (MARIA, 1994). Por isso, neste novo paradigma, a escola deve estar pronta para formar indivíduos capazes de construir conhecimentos, seres autônomos, críticos e conscientes. Esse novo pensar sobre a educação, nos leva a questionar desde a raiz desse processo, principalmente o conceito de "alfabetizado".

No mundo contemporâneo, o conceito de alfabetização não está vinculado somente à codificação e decodificação de signos, o que se configura uma atividade puramente técnica. Podemos perceber, segundo 
Silva (1991), que essa concepção de alfabetização é resultado da filosofia liberal burguesa, também conhecida como Pedagogia da Carência ou do Silêncio, que consistia em métodos que desprezavam as experiências de vida do alfabetizando, privilegiando conteúdos pré-fabricados e desvalorizando a lógica dos processos cognitivos e afetivos da criança.

Ser alfabetizado supera a aquisição apenas da técnica de decifração de códigos linguísticos permitindo principalmente que o sujeito se questione, interprete, divirta-se, seduza, sistematize, confronte, induza, documente, informe, oriente-se, reivindique e garanta a sua memória. Por isso, aprender a ler e a escrever implica não apenas no conhecimento das letras e do modo de decodificá-las (ou de associá-las), mas na possibilidade de usar esse conhecimento em benefício de formas de expressấo e comunicação, possíveis, reconhecidas, necessárias e legítimas em um determinado contexto cultural.

Dessa forma, não basta apenas que o professor ensine a ler $\mathrm{e}$ escrever, é imprescindível criar condições para que desde criança o indivíduo faça uso da leitura e escrita no seu cotidiano, além de proporcionar maior acesso a livros, filmes, bibliotecas e outros meios de aquisição do conhecimento, trazidas em ações educativas na prática de nossas escolas para que ele possa se construir enquanto sujeito ativo no mundo que o cerca.

\section{Concepções que norteiam a prática docente no processo de alfabetização}

Quando analisamos a prática de qualquer professor, vemos que por trás de suas ações há um conjunto de idéias que as orienta. Ao se tratar de alfabetização, fica mais evidente ainda que o professor precisa ter bem definido elementos como objetivos, concepções de ensino e aprendizagem, concepção de homem, papel do professor e conceitos básicos para a compreensão do processo de alfabetização. 
Ao realizar as visitas à Escola Delta ${ }^{1}$, por meio da observação de algumas situações pude reunir elementos para perceber as concepções que conduziam a prática do professor. Esta proposta de estágio por ser dividida em três momentos (observação, co-participação e regência compartilhada), me deu condições de estar em posições privilegiadas no acompanhamento da prática docente e ao mesmo tempo para pôr em prática as minhas concepções. Os estudos realizados paralelamente a este estágio revelaram o embate entre duas concepções extremas: a concepção empirista e a concepção construtiva.

Segundo Weisz (1991), a teoria empirista que historicamente vem influenciando as representações sobre o que é ensinar e o como aprender, se expressa num modelo de aprendizagem conhecido como de "estímuloresposta". Este modelo define a aprendizagem como a substituição de respostas erradas por certas. Desta forma, o aluno precisa memorizar e fixar informações que devem ir das mais simples e parciais possíveis para as mais complexas, acumulando-se com o tempo. É importante ressaltar que, na concepção empirista, o erro é visto como elemento negativo.

O método de alfabetização tradicional denominado Sintético, que está contido na concepção empirista, torna a alfabetização mecânica, muito distante de quem se pretende atingir, a criança.

Fundamentada na correspondência entre o oral e o escrito, ou seja, entre o som e a grafia, o processo de aprendizado é encarado simplesmente como a associação entre respostas sonoras a estímulos gráficos, partindo de elementos mínimos, num processo que vai das partes para o todo. Segundo este método, a aprendizagem da leitura e da escrita é um processo mecânico. Espera-se que o aprendizado da técnica garanta a decifração de um texto. Assim, por conceber a escrita como a transição gráfica da língua oral, ler equivale a decodificar o escrito em som.

\footnotetext{
${ }^{1}$ Nome fictício dado à escola para preservar os sujeitos da pesquisa, bem como o campo de coleta de dados.
} 
Desta forma, a criança é vista como um ser passivo, onde seus conhecimentos prévios não são levados em conta, sem autonomia no processo de ensino-aprendizado, fixando conteúdos sem compreensão, já que estes não têm ligação com a sua vida.

As observações realizadas na Escola Delta me levaram a perceber que a prática da professora-regente era baseada na Concepção Empirista, uma vez que por vários momentos me deparava com situações como estas:

"Ao apresentar um cartaz com o alfabeto, ela pede para que os alunos o leiam. Por terem uma sequência memorizada, qualquer equívoco na ordem parece desandar e comprometer toda a leitura. Apresentando separadamente cada letra, muitos não sabèm reconhecê-la, mas o que é solicitado pela professora é somente a seqüência do ABC de cabeça."

"Enquanto os outros terminam a atividade, ela chama os alunos que ainda não tirou a lição do dia anterior, senta num canto da sala com a criança e pede para que a criança soletre palavras da cartilha."

"A professora cola no quadro palavras sem nenhum contexto como: mala, bola e boi, escritas de várias formas, chamadas segundo ela de manuscrito, à máquina, maiúsculas e minúsculas."

"Diante da dificuldade encontrada na execução da atividade, eła (a professora) chega a colar no quadro uma tarefa mimeografada com respostas elaboradas por ela para que as crianças copiassem. ${ }^{\prime 2}$

Nos relatos supracitados pode-se perceber claramente uma aprendizagem baseada na memorização, em que o saber pensar não é levado em conta, fundamentada em atividades de cópia onde as crianças a realizam mecanicamente. Há ainda uma preocupação do professor em apresentar o tempo inteiro palavras onde o sistema de escrita é correspondente ao fonema das palavras, ou seja, por ser um método que enfatiza essa correspondência,

\footnotetext{
${ }^{2}$ Registros retirados do diário de campo
} 
palavras que não atendam a essa característica causam conflitos entre o oral e o escrito, pondo de lado a ortografia irregular.

As cartilhas ou livros de iniciação à leitura nada são mais do que a tentativa de conjugar esses princípios: evitar confusões auditivas e/ou visuais, apresentar um fonema por vez e finalmente trabalhar com a ortografia regular. As sílabas sem sentido acarretariam a consequência inevitável de dissociar (...) a leitura da fala. (FERREIRO, TEBEROSKY. 1991, p. 19)

Algumas vezes, a professora, mesmo propondo atividades partindo de textos ou de elementos significativos, sua condução acabava por reforçar sua prática empirista, como podemos observar no seguinte relato:

"A atividade parte da leitura e discussão em torno de uma parlenda. Ao pedir para identificar no texto algumas palavras, as crianças encontram dificuldades e recorrem a professora, que não faz nenhuma mé̃iação, apenas a aponta para que circulem." ${ }^{3}$

Pode-se perceber de acordo com o fragmento acima, que em momento nenhum as crianças são estimuladas a pensar, a refletir sobre a construção autônoma das palavras, segundo sua prática, é mais fácil induzilas à cópia do que estimulá-las a saber pensar.

O que mais impressiona nesse método é a negação da leitura enquanto comunicação que pode ser utilizada pela criança, reduzindo a aprendizagem à decifração, partindo de fragmentos desvinculados totalmente de sua vida. Há uma nítida desintegração ao meio social.

Tendo em vista as transformações que a sociedade moderna trouxe, já discutidas neste trabalho, o Método Sintético se apresenta inadequado às necessidades reais da criança. Sua proposta está defasada não permitindo que a criança seja ela mesma, que cresça, que pense.

\footnotetext{
${ }^{3}$ Registros retirados do diário de campo.
} 
Apesar de estas mudanças sociais sinalizarem que este modelo não cabe mais às nossas crianças, concepções de homem e de aprendizagem arraigadas num modelo skinneriano, ainda podem ser encontradas nas nossas salas de aula, mesmo depois dos avanços na Psicolinguística e Sociolinguística discutidos no Brasil nos anos 80 por Emília Ferreiro e Ana Teberosky.

Tais estudos, baseados na Teoria de Piaget, concebem o indivíduo como sujeito cognoscente, ou seja, que procura ativamente compreender o mundo que o rodeia, não um sujeito que espera que alguém transmita o conhecimento, mas que aprende através de suas próprias ações sobre os objetos do mundo (FERREIRO e TEBEROSKY, 1991).

Baseadas na Filosofia Construtivista, as autoras analisam a evolução da escrita mostrando que a criança constrói hipóteses e entra em conflito ao aplicá-las em diferentes situações, ou seja, o conhecimento é resultado da construção do próprio sujeito cognoscente.

Desta forma, considera-se como pressuposto da alfabetização que a criança percorre etapas. Segundo Ferreiro e Teberosky (1991), em relação ao seu processo de leitura, inicialmente, a criança não espera encontrar transcritas todas as palavras no texto oral. Num primeiro nível, a criança espera que somente os substantivos estejam escritos: nomes ou objetos, embora se leia um texto completo. No segundo nível, a criança admite que esteja escrito os substantivos e os verbos. Nesse nível, artigos e preposições, segundo a criança, não são escritos, pois podem ser deduzidos através dos substantivos. Outro aspecto que descaracteriza os artigos e preposições como palavras é a quantidade de letras

Para a criança, palavras com menos de três letras não são palavras, seria preciso no mínimo três letras para esta ser considerada. Finalmente a criança evolui para considerar que todos os elementos da linguagem estão escritos, superando suas etapas e abandonando suas hipóteses anteriores. 
No que diz respeito à linguagem escrita, as autoras a subdividem em níveis. Assim, no início do processo de alfabetização, as palavras consideradas como um protótipo da escrita são os substantivos, que devem ter no mínimo três letras e também uma variedade delas. Há uma busca de diferenciação entre as escritas produzidas, sem uma preocupação com as suas propriedades sonoras. Nesse nível, chamado Pré-Silábico, a criança explora tanto critérios quantitativos (variar a quantidade de letras de uma escrita para outra, obtendo escritas diferentes), quanto qualitativos (variar o repertório das letras ou a posição das mesmas sem alterar a quantidade). Não existe uma relação fonema/grafema. A correspondência entre a escrita e o nome é global, as partes da escrita não correspondem ainda às partes do nome. Cada letra pode valer pelo todo e não tem valor por si mesma, como visualizamos abaixo:

\section{ESCRITA DE MARCELO ${ }^{4}$}

(desenho)

\section{ESCRITA DE CLEITON}

(refrigerante)

ESCRITA DE JEDSON

\section{(macarrão)}

A criança, ainda nesse nível, pode se basear na concepção realística, ou seja, para ela coisas grandes se escrevem com muitas letras e coisas pequenas são escritas com nomes menores.

Outro aspecto que precisa ser observado no processo de construção da escrita da criança é a leitura. Como podemos perceber no desenho acima, as crianças fazem ainda a leitura global, ou seja, ao ler, elas não fazem

\footnotetext{
${ }^{4}$ Nomes fictícios. Escritas coletadas a partir de atividades durante o estágio.
} 
relação entre a parte da palavra lida com a sílaba referente, pois ainda não percebem que as letras correspondem ao som da fala.

O nível Silábico caracteriza-se pela correspondência entre a representação da escrita das palavras e as suas propriedades sonoras. É a descoberta de que a quantidade de letras com que se vai escrever uma palavra pode ter correspondência com a quantidade de partes que se reconhece na emissão oral. Essas partes são as sílabas e em geral a criança faz corresponder uma grafia a cada sílaba, mas ainda não é capaz de compreender todos os fonemas da sílaba, geralmente se prendendo aos sons mais fortes. Há ainda uma variação nesta hipótese: o valor sonoro. No nível silábico sem valor sonoro, a criança apesar de fazer correspondência entre sílaba e letra, tal letra não precisa representar a seu som, ao contrárí da hipótese Silábica com valor sonoro, onde tais correspondências já são efetuadas, como podemos ver nas escritas abaixo:

\section{ESCRITA DE ALANDA}

(calypso)

\section{ESCRITA DE JOANDERSON}

\section{(Vermelho)}

O nível silábico é um salto qualitativo no processo de aquisição da escrita, pois é uma construção individual em que houve a superação da etapa anterior. Em relação à leitura, o mesmo que acontecia no nível pré-silábico não acontece com estas escritas. As crianças, agora, realizam leituras com pausas, pois já percebem que a grafia de cada sílaba da palavra corresponde aos sons que emitimos pausadamente ao pronunciar as palavras.

A evolução do nível Silábico para o Silábico-Alfabético leva a criança a estabelecer que as partes sonoras semelhantes entre as palavras se exprimem por letras semelhantes. Neste nível existem duas formas de correspondência entre sons e grafias: silábica (sílaba é o som produzido por uma só emissão de voz) e alfabética (análise dos fonemas, que são 
elementos sonoros da linguagem e tem nas letras o seu correspondente). Assim, a criança escreve parte da palavra aplicando a hipótese silábica (de que para se escrever uma sílaba é necessário apenas uma letra) e escreve parte da palavra aplicando a alfabética (fazendo a análise fonética). Isso se verifica nos exemplos abaixo:

\section{ESCRITA DE LUCILEIDE}

(novela)

(suco)

O nível posterior é denominado Alfabético e se caracteriza pela correspondência entre som e letra. Existe a compreensão da escrita alfabética onde todos os fonemas devem estar representados. A análisé se aprimora e é possível a compreensão de que uma sílaba pode ter uma, duas ou três letras. Pode haver também erros ortográficos sem ligação sonora. Estes só serão apreendidos pela criança através da memória visual (leituras) ou por mediação de um parceiro ou adulto. Podemos percebê-la abaixo:

ESCRITA DE MOISÉS

(pagode)

\section{ESCRITA DE GLÍCIA}

(amarelo)

\section{ESCRITA DE LUIZ HENRIQUE}

(azul)

A passagem da escrita da criança de um nível para outro está diretamente ligada ao conhecimento anterior. O tempo em que ela permanece num mesmo nível é muito variável. Por outro lado, essa evolução não é linear, pois a criança passa por avanços e recuos durante todo o seu processo de construção da escrita, ainda que seu desenvolvimento esteja diretamente relacionado com seu nível inicial de 
conceitualização da escrita. É nessa fase que a intervenção do professor é de extrema importância.

Outro aspecto que chama atenção no processo de construção da escrita da criança é a memória visual. Por estar acostumada a ver palavras escritas no seu cotidiano ela as memoriza e ao escrevê-la, reproduz por conta das lembranças visuais. É o que podemos perceber nas escritas abaixo, mesmo em crianças ainda não-alfabéticas:

\section{ESCRITA DE CARLOS}

(kapo)

\section{ESCRITA DE LUCILEIDE}

(Coca Cola)

Deste modo, o professor-alfabetizador deve conhecer o estágib de desenvolvimento cognitivo que está o educando, bem como seu nível de evolução da escrita. Assim, ele pode organizar atividades que gerem conflitos cognitivos e que possibilitem a construção da leitura e da escrita pelo próprio aprendiz, levando-o a pensar, selecionar, optar e conferir suas escolhas, refazendo-as se necessário. Isso só será possível se ele planejar e direcionar atividades que envolvam o aprendiz como ser ativo no seu processo de aprendizagem.

O professor-alfabetizador deve também assumir postura de investigador, analisando tudo que o alfabetizando produz, descobrindo o que ele já domina e utilizando seus erros para compreender sua forma de pensar. Neste processo, as parcerias são também muito importantes. Ao identificar o nível de leitura e escrita de cada um, o professor deve utilizá-las de modo a proporcionar uma troca entre os indivíduos visando à aprendizagem mútua.

Por acreditar que a criança é um ser ativo e capaz de construir seu próprio conhecimento foi que no período da Regência pude pôr em prática minhas concepções, a fim de contribuir para o processo de aprendizado daquelas crianças. 


\section{Regência: impasses e perspectivas}

Considero essa proposta de estágio de fundamental importância para a formação docente, pois, como ouvimos freqüentemente, o professor iniciante possui certa ingenuidade referente às questões reais ao sair da academia entrando em contato com a prática. Apesar das diferentes instituições e situações que cada um de nós vivenciamos ao estarmos inseridas neste estágio, pude conhecer aspectos da realidade escolar e refletir a cerca de toda a teoria estudada até aqui, a fim de interferir nela à luz de elementos teóricos para contribuir com o maior foco da educação: a aprendizagem.

Pelo fato do tempo ser curto, era muito difícil adentrar no espaço escolar, elementos desconhecidos naquele ambiente, e começarmos um trabalho individual. Seria muito egoísmo não se preocupar e não perceber os desequilíbrios causados pela minha presença. Só depois de algum tempo é que poderiam os perceber que já havíamos estabelecido um vínculo capaz de não causar tais desequilíbrios.

Outro aspecto que chama atenção nesta proposta é a incapacidade de causar mudanças profundas. Minha inserção na Instituição se deu quando já havia uma rotina, costumes, hábitos, práticas pedagógicas consolidadas, as quais, mesmo julgadas por mim, inadequadas, seriam praticamente impossíveis de mudar no momento da co-participação e regência, pois seria um tempo muito curto pra transformar todo um contexto.

A observação foi um momento crucial no estágio, pois através dos elementos observados neste período, pude refletir acerca da questão central que merecia maior investimento no período da regência. Além disso, a preocupação da professora contou muito para essa escolha. Eram crianças de 7 a 12 anos que caminhavam muito vagarosamente no processo de alfabetização, cuja condução docente neste processo dificultava seu desenvolvimento e deixavam marcas quase que irrevogáveis nas crianças. 
Por conta destes elementos escolhi trabalhar com leitura e escrita, mas já consciente de que não conseguiria causar mudanças naquela realidade por conta do tempo, acreditando na sequência que o professor poderia dar aos trabalhos.

Segundo Weisz (1999), há uma estreita relação entre a repetência na primeira série do Ensino Fundamental e a falta de acesso à Educação Infantil, pois a formação de todas as habilidades que a criança necessitará para chegar à primeira série é feita na Educação Infantil, sem estas a criança terá maiores dificuldades para construir a leitura e a escrita. Pude constatar, através de conversas informais, que quase $80 \%$ das crianças não haviam frequentado a Educação Infantil, não tendo assim, uma preparação formal para ingressar na primeira série, desprezando o desenvolvimento das habilidades necessárias nesta transição. Outro dado importante coletado da mesma maneira, é que $65 \%$ das crianças eram repetentes, comprovando essa relação.

Pode-se perceber, majoritariamente, a inadequação idade/série causadas por sucessivas repetências na primeira série, o que reduz a autoestima das crianças, muitas vezes se percebendo incapazes de serem bem-sucedidos na escola, reforçando o estigma de que classes menos abastadas geralmente fracassam na escola, refletindo em sư posições na base da pirâmide social.

Como já foi relatado no tópico anterior, este estágio trouxe o embate entre duas concepções: a empirista, que embasava a prática da professora; e a construtivista, na qual, através de seus relatos, parecia acreditar. Através das minhas observações e reflexões, pude perceber a presença constante da cópia na sala de aula, o que representava uma muleta para as crianças, desmotivando seu raciocínio na construção das hipóteses de leitura e escrita. Esse aspecto me preocupava a respeito da reação das crianças ao estimular a escrita livre de cópias, baseadas na sua crença de construção. 
Ou seja, eram práticas muito diferenciadas que trariam certo desequilíbrio na sala de aula e dificultaria o andamento da minha proposta.

Em nenhum momento antes da Regência, tive a oportunidade de vivenciar situações que me permitisse conhecer as hipóteses de escrita das crianças. Todas as atividades eram baseadas em cópia no quadro, de um cartaz, de palavras do livro, dificultando o diagnóstico prévio destas hipóteses, ou seja, para planejar atividades coerentes, precisava saber o que as crianças já sabiam para que as interferências e situações de aprendizagem fossem válidas para o desenvolvimento dos alunos, mas estes momentos não ocorriam, pois as crianças não tinham momentos de produção autônoma.

Desta forma, precisei, no momento de Regência, realizar atividảdes que me dessem margem para conhecer estas hipóteses de escrita, ou seja, atividades diagnósticas para que a partir daí os fizesse avançar, o que não seria fácil em apenas 20 horas com quase 30 alunos.

Apesar de pouco tempo, pude perceber que os níveis cognitivos de cada criança eram muito diferenciados chegando a hipóteses extremas, das garatujas à alfabética com erros ortográficos. Esse diagnóstico realizado ao longo de toda a regência, não foi um diagnóstico preciso, pois tive pouco tempo de contato para apresentá-lo com exatidão. Alguns deles foram apresentados no tópico anterior para explicitar tais hipóteses.

Outro fator importante a ser descrito, ocorrido no período da regência, foi a recusa de algumas crianças a escreverem livre de cópias. Ao perceberem a ausência de um modelo onde se viam forçados a pensar para escrever, algumas crianças se negavam a arriscar, outras simplesmente utilizavam estratégias para saírem daquele conflito, como copiar o enunciado da atividade, pedir para o colega fazer para ela ou copiar do colega. Aquela situação era para eles, um conflito angustiante, onde precisavam encontrar saídas para resolver aquele problema que pela primeira vez era colocado: saber pensar. Até mesmo em atividades com o 
intuito de estimular a criatividade através de ilustrações, estas eram quase sempre copiadas de cartazes da sala.

Além do mais, havia uma preocupação constante em estar mostrando as respostas ao professor para que ele julgasse estar correto eu não. Naquele momento, o meu interesse não era apurar erros e acertos, mas sim perceber como concebiam a construção da escrita das palavras. Mesmo pedindo para que não se preocupassem com este fator, percebia que para eles o acerto era mais importante do que um erro capaz de fazê-los aprender, marcas da valorização excessiva de respostas corretas.

Além de observar os alunos na execução das atividades, observei também a professora que auxiliava no período da Regência, fazendo mediações junto às crianças nas atividades propostas. Mesmo explicitando e esclarecendo a minha proposta pedagógica baseada em Emília Ferreiro e Ana Teberosky para conduzir as atividades, a professora aindá fazia intervenções forçando as crianças a escreverem convencionalmente, desrespeitando suas hipóteses, o que dificultava o alcance dos objetivos. Mesmo tendo uma formação superior em Pedagogia e ter estudado sobre a Psicolinguística e Sociolinguística, esta reflexão teoria-prática não era feito por ela, muitas vezes explicitando em sua fala sua incredibilidade em tal concepção. Esse fato me chamou muita atenção, mas renderia outro estudo sobre as influências e os (des)caminhos que a formação docente toma na construção e ressignificação de tais teorias durante o percurso teoria-prática.

Diante de tais aspectos e por estar convencida de que seria difícil promover mudanças significativas naquele contexto em tão pouco tempo, elegi como objetivo principal no período da Regência a promoção de momentos de leitura e escrita até então negados pela presença da cópia constante, onde as crianças poderiam se perceber sujeitos de sua aprendizagem na construção do conhecimento.

Ao final desta experiência, estive em contato com sensações diferenciadas. Angústia, por ver em certos momentos a agressividade, a 
indisciplina, a falta de apoio da direção, a ausência da coordenação escolar, a falta de parceria com a família, os problemas sociais que cercam aquela comunidade, mas uma alegria e satisfação em perceber que o adormecimento daquelas crianças naquele momento poderia ser cessado através de iniciativas pedagógicas que valorizassem a criança como um ser capaz de aprender e produzir conhecimento.

Neste sentido, sabe-se que a formação do professor pode contribuir decisivamente na prática docente. Entretanto, como se pode observar na experiência do estágio, este fator não é determinante. Segundo Freire (1996), o professor precisa assumir o compromisso de educar. Assim, o profissional docente deve estar no mundo e se saber como ser estando nele, ou seja, conhecer sua realidade e ser capaz de operar sobre ela.

Sem esse compromisso social, a educação assume um sentido bancário, ou seja, como sugere Freire (1996), um processo educativo sem o poder reflexivo e conscientizador se faz através de comunicados aos educandos numa relação vertical, recebidos passivamente. Esse processo "mata o poder criador não só do educando, mas também do educador." (FREIRE, 1996, p.69), na medida em que se transforma na doação de fórmulas e receitas sem considerar o conhecimento de mundo e a realidade dos alunos.

Penso que esta transformação social através da educação não é uma tarefa fácil para os educadores, mas ensinar e aprender exige a convicção de que a mudança é possível, exige, pois, esperança. Exige amor à profissão e também aos educandos.

\section{Conclusão}

Ao final da elaboração deste trabalho baseado numa experiência de estágio vivenciado durante a graduação, pude perceber quantas situações como estas podem auxiliar na formação docente, a partir do momento em 
que possibilita a articulação da teoria estudada na academia e os reais problemas da educação, contribuindo para a construção da identidade docente, suscitando a prática reflexiva, sendo possível alcançar uma compreensão mais elaborada da realidade, examinando seus pressupostos, com a necessária mediação da teoria e seus desdobramentos.

No entanto, se a prática docente for dissociada dos saberes estudados na academia, a condução dos trabalhos realizados em sala de aula não levará o educando a desenvolver a autonomia intelectual na construção do conhecimento, dando lugar, assim, à reprodução.

$\mathrm{Na}$ perspectiva de uma sociedade em transformação, faz-se necessário auxiliar o educando a refletir sobre o seu processo de leitura e escrita, não podendo, assim, admitir receitas prontas, mas sim, desafios constantes.

Cabe ressaltar também, que a criança precisa de um ambiente alfabetizador, em que as práticas sociais da leitura e escrita façam parte do seu cotidiano, promovendo uma aprendizagem mais autêntica e significativa, admitindo que o processo de alfabetização não seja algo finito〔 mas deve ser encarado como algo a ser desenvolvido e estimulado ao longo da vida.

Diante do que foi exposto, cabe ao professor-alfabetizador estar imbuído num processo de tomada de consciência, na busca constante da ação-reflexão se responsabilizando pela formação dos indivíduos para que estes construam a competência do saber-pensar, tão necessária para sua inserção no mundo atual.

\section{Referências bibliográficas}

FERREIRO, E.. TEBEROSKY, A.. Psicogênese da língua escrita. Porto Alegre: Artes Médicas, 1991. 
FEIL, I. T. S.. Alfabetização - um desafio novo para um novo tempo. Rio Grande do Sul: Vozes/FIDENE, 1984.

FRANCO, Â.. Metodologia de ensino: língua portuguesa, Belo Horizonte, MG: Ed. Lê Fundação Helena Antipoff, 1997 (ColeçãoApoio).

FREIRE. P.. Pedagogia da autonomia - Saberes Necessários à Prática Educativa. São Paulo: Paz e Terra, 1996.

MARIA, L. de. Constituição do leitor. Simpósio Nacional de Leitura, Rio de Janeiro, PROLER/FBN/CCBB, 1994.

SILVA, E. T. Da. De olhos abertos: reflexões sobre o desenvolvimento da leitura no Brasil. São Paulo: Editora Àtica, 1991.

WEISZ, T.. O Diálogo entre o ensino e a aprendizagem. São Paulo: Ática, 1999.

\section{Autora:}

Fabiana Castelo Branco de Santana

Universidade Estadual de Feira de Santana

Contato: fabipedagoga@gmail.com

Texto recebido em outubro de 2011.

Texto aprovado para publicação em janeiro de 2012.

\section{Como citar este texto:}

SANTANA, F. C. B. de. Alfabetização: um desafio para um novo tempo, Revista Acolhendo a alfabetização nos países de língua portuguesa, Brasil, São Paulo, volume 1, nº 12, p. 66 -84, Mar. 2012. Disponível em: $<$ http://www.acoalfaplp.net>. 